\title{
NORMAL LEVELS OF TSH AFFECT THE METABOLLC PROFILE DIFFERENTLY IN PHYSICALLY ACTIVE MALES AND FEMALES
}

\author{
Marzena Malara ${ }^{A, B, C, D, E}$ \\ Department of Human Biology, Józef Piłsudski University of Physical Education, Warsaw, Poland \\ ORCID: 0000-0003-0765-8318 | email: marzena.malara@awf.edu.pl
}

\section{Anna Kęska ${ }^{B}$}

Department of Human Biology, Józef Piłsudski University of Physical Education, Warsaw, Poland ORCID: 0000-0002-9829-0872

\section{Joanna Tkaczyk ${ }^{\mathrm{B}}$}

Department of Human Biology, Józef Piłsudski University of Physical Education, Warsaw, Poland ORCID: 0000-0002-6910-5412

\section{Grażyna Lutosławska ${ }^{A, D}$}

\author{
Department of Human Biology, Józef Piłsudski University of Physical Education, Warsaw, Poland

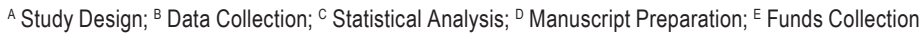

\begin{abstract}
Ahstract Our study was aimed at the evaluation of relationships between thyroid stimulating hormone (TSH) within the normal range and metabolic risk factors (glucose, insulin, HOMA-IR and lipoprotein profile) in physically active male and female students. In 219 students circulating TSH, glucose, insulin and lipoproteins were measured in blood under fasting conditions. Insulin resistance was expressed as HOMA-IR (homeostasis model assessment for insulin resistance). For further procedures 99 males and 97 regularly menstruating females with TSH $0.4-4.0 \mu \mathrm{lU} / \mathrm{ml}$ were accepted. In male students no correlations between circulating TSH, anthropometric and biochemical variables were noted. In females TSH within the normal range was slightly but significantly correlated with the triglyceride (TG) level $(p<0.03)$. However, step-wise multiple regression analysis revealed that the effect of TSH was small $(p<0.046)$ in relation to that found for HOMA-IR $(p<0.0009)$. No relationships between biochemical variables and normal levels of TSH were noted in male students. However, surprisingly normal range TSH in males was slightly but significantly correlated with the percentage of body fat and this issue needs further studies concerning measurements of different fat depots. The above data suggests that in active females TG synthesis and export from the liver is more sensitive to TSH action than in active male counterparts.
\end{abstract}

Key Worlds normal range TSH, glucose, insulin, HOMA-IR, lipoproteins 


\section{Introduction}

Numerous studies have shown that variability in circulating TSH within the normal range affects circulating lipids (Asvold, Vatten, Nilsen, Bjøro T, 2007; Lee et al., 2019 ). However, this issue was studied mostly in middleaged and older adults as a consequence of increased thyroid gland disease with age (Chen et al., 2018; Lo Sasso, Vidali, Scazzone, Agnello, Ciaccio, 2019). Data concerning metabolic effects of variability in normal level circulating TSH in young adults are scarce and their results are interpreted for combined male and female participants (Joseph, Chettuvatti, Yadav, Bharadwaj, Kotian, 2017; Rahbar et al., 2017). On the other hand, it is well documented that sex hormones significantly contribute to the regulation of thyroid function due to functional associations between the hypothalamic-pituitary-thyroid axis (HPT) and the hypothalamic - pituitary gonadal axis (HPG) at least in part due to estrogen and androgen receptor expression in thyroid glands (Schaefer, Geelhoed, Dadu, 1986; Marugo et al., 1991). Thus, the above data suggest that studies concerning TSH effects on metabolic processes have to be interpreted separately in males and females due to differences in sex hormone status.

Additionally, many data have provided discordant results concerning associations of circulating TSH and physical activity. In young men both no changes and significant elevation in circulating TSH were noted immediately after maximal aerobic exercise (Ciloglu et al., 2005; Huang et al., 2004; Beyleroglu, 2011). In addition it was shown that long term exercise may have different impacts on TSH levels than an acute exercise program (Hawamdeh, Baniata, Mansi, Nasr, Aburjai, 2012). However, no changes in circulating TSH were observed in elite athletes who underwent regular training (Healy, Gibney, Pentecost, Wheeler, Sonksen, 2014; de Souza et al., 2019; Ceresini et al., 2019). With this background in mind our study was undertaken and was aimed at evaluation of relationships between circulating TSH within the normal range with metabolic risk factors (glucose, insulin, lipoproteins) separately in male and female physical education students engaged in regular physical activity due to their studies. In 112 male and 107 female students circulating TSH, glucose, insulin and lipoproteins were measured in blood under fasting conditions. For further procedures exclusively those with TSH $0.4-4.0 \mu \mathrm{lU} / \mathrm{ml}$ were selected.

\section{Material and methods}

\section{Subjects}

Physical education students were recruited by word of mouth and advertisements in student dormitories. Exclusively regularly physically active healthy non-smokers not taking supplements on a regular basis were accepted. None of them were high-performance athletes, however, all volunteers had been active for at least 3 months and were engaged in different forms of physical activity due to their study program (gymnastics, swimming, basketball, dance for 6 hours/week). Finally 112 males and 148 females were accepted and underwent further procedures. All 148 female students were asked about oral contraceptive $(\mathrm{OC})$ use and $25 \mathrm{OC}$ users were excluded from the study. Thus 123 females were asked to provide information concerning menstrual cycle regularity. In consequence exclusively 107 females with cycle length 21-35 days were accepted for participation (Dasharathy et al., 2012). All participants provided written consent for participation in the study and the study protocol was accepted by the local Ethics Commission. 


\section{Anthropometry}

In 112 male and 107 female subjects mass and height were determined in barefooted participants wearing light clothes using standard medical equipment. The precision of body mass and height determination was $0.1 \mathrm{~kg}$ and $0.1 \mathrm{~cm}$, respectively. Body fatness was determined using measurements of 4 skinfolds (biceps, triceps, suprailiac and subscapular) with Harpenden caliper (British Indicators, Burges HILL, UK) and calculated according to Durnin and Womersley (1974). All measurements were done twice by a trained technician and in the case of discrepancy were repeated for the third time. Lean body mass (LBM) was also calculated.

\section{Biochemical analysis}

A total of 112 males and 107 females were accepted for blood analysis. All subjects were asked to refrain from physical activity for at least $8 \mathrm{~h}$ and to eat their last meal at least $12 \mathrm{~h}$ before blood withdrawal. Blood was taken under aseptic conditions into plastic tubes with anticoagulant and centrifuged $15 \mathrm{~min}$ to obtain plasma which was stored at $-70^{\circ} \mathrm{C}$ until analysis. Plasma glucose was determined using the GOD-PAP method. Triacylglycerols (TG), total cholesterol (TC) and HDL-cholesterol (HDL-C) were assayed with colorimetric methods and commercial kits (Randox Laboratories, UK). Coefficients of variation for all variables did not exceed $5 \%$. The plasma concentration of LDL-cholesterol (LDL-C) was calculated according to the Friedewald, Levy, Fredricson (1972) formula. Plasma insulin was measured using a standard radioimmunoassay (RIA) with human monoclonal antibodies against insulin and commercial kits (BioSource, Belgium). Inter- and intra-assay coefficients of variation for insulin determination did not exceed $7 \%$. All measurements were done in duplicate. Insulin resistance index (HOMA-IR) was calculated according to the Mathews et al. (1995) formula:

$$
\text { HOMA-IR = [glucose }(\mathrm{mmol} / \mathrm{L}) \times \text { insulin }(\mu \mathrm{lU} / \mathrm{ml})] / 22.5 \text {. }
$$

\section{Subjects' classification according to normal plasma TSH}

Circulating thyroid hormone (TSH) was assayed using a standard immunoassay method (RIA) and commercial kits (BioSource (Belgium) Inter- and intra- assay coefficients of variation for TSH determination did not exceed 7\%.

The results of circulating TSH were used to identify subjects with normal circulating hormone TSH levels established between 0.4-4.0 $\mu \mathrm{lU} / \mathrm{ml}$ according to Pearce et al. (2013). In consequence, a total of 99 males and 97 regularly menstruating females participated in the analysis of TSH relationship with other metabolic variables (glucose, insulin, HOMA-IR and lipoproteins) (Figure 1). 

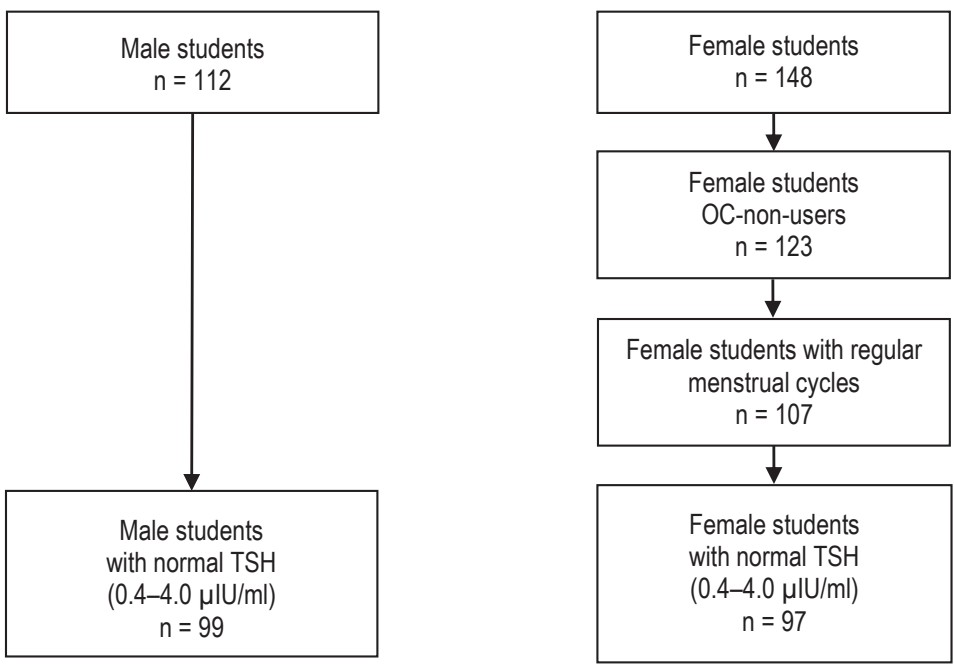

Figure 1. Classification of study participants according to circulating TSH.

\section{Statistical analysis}

Data were tested for normality using the Shapiro-Wilk test. The differences between male and female students were evaluated using the Mann-Whitney test. In both male and female students Pearson's correlation was used to test the association between TSH and other variables. In addition, in females step-wise regression analysis was performed to determine the contribution of TSH to the variability of the TG plasma levels. Both analyses were performed for logarithmically transformed data (base 10). Descriptive statistics are presented as mean \pm SD. Significance of differences was established at $p<0.05$. All calculations were performed using STATISTCA for Windows, v.12.0 (Stat Soft, USA).

\section{Resullts}

Body composition and metabolic variables in male and female participants with normal TSH are presented in Table 1 with males with significantly higher body mass, body height but lower percentage of body fat in comparison with females ( $p<0.001$ for all variables). Females were characterized by significantly higher circulating insulin vs. males $(p<0.001)$ In consequence, HOMA-IR in females was markedly higher in comparison with males (1.480 vs. 1.128, $p<0.005)$. There were no sex-related differences in plasma levels of TG, TC and LDL-C. However, circulating HDL-C in females was higher by $28.5 \%$ than in males $(p<0.001)$. In male students a slight, but significant correlation was found between circulating TSH and the percentage of body fat $(p<0.03)$ but no correlations of TSH with biochemical variables were noted (Table 2). On the contrary, in female students circulating TSH was not related to the percentage of body fat but a slight and significant correlation was noted with plasma TG $(p<0.03)$. 
Tahle 1. Anthropometric and biochemical characteristics of physically active male and female students with normal TSH levels $(0.4-4.0 \mu \mathrm{lU} / \mathrm{ml})$

\begin{tabular}{lcc}
\hline \multicolumn{1}{c}{ Variables } & $\begin{array}{c}\text { Males } \\
(\mathrm{n}=99)\end{array}$ & $\begin{array}{c}\text { Females } \\
(\mathrm{n}=97)\end{array}$ \\
\hline Age (years) & $21.1 \pm 2.1$ & $21.1 \pm 1.5$ \\
Weight $(\mathrm{kg})$ & $78.4 \pm 10.0$ & $62.2 \pm 8.5^{\mathrm{a}}$ \\
Height $(\mathrm{cm})$ & $182.0 \pm 6.7$ & $167.9 \pm 5.7^{\mathrm{a}}$ \\
Fat $(\%)$ & $11.6 \pm 4.8$ & $25.2 \pm 5.2^{\mathrm{a}}$ \\
Fat $(\mathrm{kg})$ & $9.1 \pm 4.7$ & $15.7 \pm 6.0^{\mathrm{a}}$ \\
LBM $(\mathrm{kg})^{\wedge}$ & $69.3 \pm 7.7$ & $46.5 \pm 4.1^{\mathrm{a}}$ \\
TSH $(\mu / \mathrm{U} / \mathrm{ml})^{\#}$ & $2.3 \pm 0.8$ & $2.2 \pm 0.8$ \\
Glucose $(\mathrm{mmol} / \mathrm{L})$ & $4.7 \pm 0.3$ & $4.5 \pm 0.3^{\mathrm{a}}$ \\
Insulin $(\mu / \mathrm{lU} / \mathrm{ml})$ & $5.4 \pm 2.4$ & $7.4 \pm 4.8^{\mathrm{a}}$ \\
HOMA-IR & $1.128 \pm 0.535$ & $1.480 \pm 0.932^{\mathrm{b}}$ \\
TG $(\mathrm{mmol} / \mathrm{L})$ & $0.9 \pm 0.4$ & $0.8 \pm 0.3$ \\
TC $(\mathrm{mmol} / \mathrm{L})$ & $4.3 \pm 0.8$ & $4.4 \pm 0.6$ \\
HDL-C $(\mathrm{mmol} / \mathrm{L})$ & $1.4 \pm 0.3$ & $1.8 \pm 0.3^{\mathrm{a}}$ \\
LDL-C (mmol/L) & $2.2 \pm 0.6$ & $2.2 \pm 0.6$ \\
\hline
\end{tabular}

"LBM - lean body mass; " TSH-thyroid stimulating hormone.

HOMA-IR - insulin resistance; TG - triacylglycerols; TC - total cholesterol; HDL-C - HDL-cholesterol; LDL-C - LDL-cholesterol. ${ }^{a} \mathrm{P}<0.001 ;{ }^{\mathrm{b}} \mathrm{P}<0.005-$ significantly higher vs. males.

Tahle 2. Pearson's correlation coefficients between normal TSH level, anthropometry and biochemical variables in active male and female students

\begin{tabular}{lrc}
\hline \multicolumn{1}{c}{ Variables } & $\begin{array}{c}\text { Males } \\
(\mathrm{n}=99)\end{array}$ & $\begin{array}{c}\text { Females } \\
(\mathrm{n}=97)\end{array}$ \\
\hline Fat $(\%)$ & $\mathbf{0 . 2 2 6 ^ { \mathrm { a } }}$ & 0.002 \\
Glucose $(\mathrm{mmol} / \mathrm{L})$ & -0.020 & 0.090 \\
Insulin $(\mu / \mathrm{U} / \mathrm{ml})$ & 0.040 & 0.105 \\
HOMA-IR & 0.001 & 0.113 \\
TG $(\mathrm{mmol} / \mathrm{L})$ & -0.120 & $0.230^{\mathrm{a}}$ \\
TC $(\mathrm{mmol} / \mathrm{L})$ & -0.040 & 0.001 \\
HDL-C $(\mathrm{mmol} / \mathrm{L})$ & 0.080 & 0.178 \\
LDL-C $(\mathrm{mmol} / \mathrm{L})$ & -0.050 & -0.150 \\
\hline
\end{tabular}

Abbreviations: see Table 1; ' all data were logarithmically transformed (base 10) before calculation; ${ }^{\text {a }}<<0.030$.

In females step-wise multiple regression analysis revealed that circulating TG was positively and significantly correlated with HOMA-IR ( $p=0.0002)$ with slight but significant contribution of plasma TSH to the variability of TG $(p=0.046)$ (Table 3$)$. In the case of male students all data were excluded from step-wise multiple regression model. 
Table 3. Step-wise multiple regression analysis for the relationship between TG and HDL-C with TSH and HOMA-IR in active female students with normal TSH levels

\begin{tabular}{cccccc}
\hline Dependent variable & Independent variables & B & SD & t & p \\
\hline TG $^{*}$ & HOMA-IR & 0.359 & 0.094 & 3.820 & 0.0002 \\
& TSH & 0.189 & 0.094 & 2.017 & 0.0460 \\
\hline Corrected $\mathrm{R}^{2}=0.162, \mathrm{~F}(2.94)=10.338, \mathrm{p}<0.00009$ & & &
\end{tabular}

For abbreviations - see Table 1; " - all data were logarithmically transformed before analysis (base 10).

\section{Discussion}

The most important finding of our study indicated that active female subjects differ in respect to the relationship between normal level TSH with circulating TG vs. their male counterparts.

In male students no correlations between circulating TSH, anthropometric and biochemical variables were noted. This is in agreement with other data indicating a direct effect of thyroid hormones on hepatic lipid metabolism (Sinha, Singh, Yen, 2018; Duntas, Brenta, 2018). In addition there are data which noted that in middle age subjects TG efflux from the liver is to a greater extent stimulated by TSH in females than in males (Tognini et al., 2012). However, multiple regression analysis indicated that TSH contribution is close to the limit of significance, with powerful contribution of insulin resistance expressed as HOMA-IR. It is well documented that TG synthesis in the liver is markedly stimulated in response to elevated insulin resistance (Scherer et al., 2016; Pramfalk et al., 2016). Thus, it could be postulated that in active females the role of insulin resistance in the regulation of circulating TG is more pronounced than that of blood TSH within the normal range. On the other hand, it could be tentatively postulated that the effect of TSH on TG will be more pronounced with an increase in its plasma level observed with age in both sexes (Ehrenkranz et al., 2015; Wang et al., 2018). In this context the role of TG in the development of cardiovascular disease in women has to be taken into consideration (Boullart, de Graaf, Stalenhoef, 2012; Budoff, 2016). Interestingly, data for active male students did not demonstrate any relationship between circulating normal range TSH with TG. Thus it could be suggested that different steps of TG metabolism in active males are less sensitive to variability of TSH within the normal range. Therefore, the age and sex of the subjects, as well as the range of TSH level in the blood, seem to be of key importance for the assessment of its influence on the metabolism of hepatic lipid metabolism.

Surprisingly, a slight but significant associations of TSH with the percentage of body fat was found exclusively in male students, thus in subjects with significantly lower fatness vs. their female counterparts. The reason for this finding could be only speculated and further studies are needed concerning regional fat distribution (e.g. visceral and/or epicardial) in both active males and females in the context of normal circulating TSH (Korkmaz et al., 2013; Belen et al., 2015; Sayin et al., 2016).

\section{Conclusions}

In summary, our study indicated that circulating TG in physically active females is more sensitive to variability in TSH within the normal range in comparison with their male counterparts. However, the contribution of TSH although significant is much lower than that of insulin resistance expressed as HOMA-IR. According to our best knowledge this study is the first which focused on the effect of normal TSH levels on the metabolic profile in young, 
active participants of both sexes. However, the limitations of our study have to be underlined and are focused on the lack of the determination of adipokines (e.g. leptin and adiponectin) but also of the adipo-myokine irisin which possibly affect circulating TSH and whose levels differ with respect to sex. Moreover, it seems that in males more precise determination of body fat is of importance.

\section{Acknowledgements}

We express our thanks to all students participating in the study.

\section{References}

Asvold, B.O., Vatten, L.J., Nilsen, T.I., Bjøro, T. (2007). The association between TSH within the reference range and serum lipid concentrations in a population-based study. The HUNT Study. European Journal of Endocrinology, 156 (2), 181-186. DOI: 10.1530/eje.1.02333.

Belen, E., Değirmencioğlu, A., Zencirci, E., Tipi, F.F., Altun, Ö., Karakuş, G., Ayşen Helvacı, A., Zencirci, A.E., Kalaycıoğlu, E. (2015). The association between subclinical hypothyroidism and epicardial adipose tissue thickness. Korean Circulation Journal, 45, 210-215. DOI: 10.4070/kcj.2015.45.3.210.

Beyleroglu, M. (2011). The effects of maximal aerobic exercise on cortisol and thyroid hormones in male field hockey players. African Journal of Pharmacy an Pharmacology, 5 (17), 2002-2006. DOI: 10.5897/AJPP11.229.

Boullart, A.C., de Graaf, J., Stalenhoef, A.F. (2012). Serum triglycerides and risk of cardiovascular disease. Biochimica et Biophysica Acta, 1821 (5), 867-785. DOI: 10.1016/j.bbalip.2011.10.002.

Budoff, M. (2016). Triglycerides and triglyceride-rich lipoproteins in the causal pathway of cardiovascular disease. American Journal of Cardiology, 118 (1), 138-145. DOI: 10.1016/j.amjcard.2016.04.004.

Ceresini, G., Marina, M., Lauretani, F., Maggio, M., Serra, M.F., Meschi, T., Bandinelli, S., Ceda, G.P., Ferrucci, L. (2019). Physical performance across the thyroid function values within the normal range in adult and older persons. Aging Clinical and Experimental Research, 31 (3), 385-391. DOI: 10.1007/s40520-018-0975-0.

Chen, Y., Chen, Y., Wang, N., Chen, C., Nie, X., Li, Q., Han, B., Lu, Y. (2018). Thyroid stimulating hormone within the reference range is associated with visceral adiposity index and lipid accumulation product: A population-based study of SPECT-China. Hormone and Metabolic Research, 50 (1), 29-36. DOI: 10.1055/s-0043-122235.

Ciloglu, F., Peker, I., Pehlivan, A., Karacabey, K., Ilhan, N., Saygin, O., Ozmerdivenli, R. (2005). Exercise intensity and its effects on thyroid hormones. Neuroendocrinology Letters, 26 (6), 830-834.

Dasharathy, S.S., Mumford, S.L., Pollack, A.Z., Perkins, N.J., Mattison, D.R., Wactawski-Wende, J., Schisterman, E.F. (2012). Menstrual bleeding patterns among regularly menstruating women. American Journal of Epidemiology, 175 (6), 36-545. DOI: 10.1093/aje/ kwr356.

de Souza, H.S., Jardim, T.V., Barroso, W.K.S., de Oliveira Vitorino, P.V., Souza, A.L.L., Jardim, P.C.V. (2019). Hormonal assessment of participants in a long distance walk. Diabetology \& Metabolic Syndrome, 11, 19. DOI: 10.1186/s13098-019-0414-1.

Duntas, L.H., Brenta, G. (2018). A renewed focus on the association between thyroid hormones and lipid metabolism. Frontiers in Endocrinology, 9, 511. DOI: 10.3389/fendo.2018.00511.

Durnin, J.V., Womersley, J. (1974). Body fat assessment from total body density and its estimation from skinfold thickness: measurements on 481 men and women aged from 16 to 72 years. British Journal of Nutrition, 32 (1), 77-97. DOI: DOI: 10.1079/BJN19740060.

Ehrenkranz, J., Bach, P.R., Snow, G.L., Schneider, A., Lee, J.L., Ilstrup, S., Bennett, S.T., Benvenga, S. (2015). Circadian and circannual rhythms in thyroid hormones: determining the TSH and free T4 reference intervals based upon time of day, age, and sex. Thyroid, 25 (8), 954-961. DOI: 10.1089/thy.2014.0589.

Friedewald, W.T., Levy, R., Fredricson, D. (1972). Estimations of low-density lipoprotein concentrations without use the preparative ultra-centrifugation. Clinical Chemistry, 18 (6), 499-504. DOI: 10.1093/clinchem/18.6.499.

Hawamdeh, Z., Baniata, A., Mansi, K., Nasr, H., Aburjai, T. (2012).Thyroid hormones levels in Jordanian athletes participating in aerobic and anaerobic activities. Scientific research and essays, 7 (19), 1840-1845. DOI: 10.5897/SRE11.1734.

Healy, M.L., Gibney, J., Pentecost, C., Wheeler, M.J., Sonksen, P.H. (2014). Endocrine profiles in 693 elite athletes in the postcompetition setting. Clinical Endocrinology, 81 (2), 294-305. DOI: 10.1111/cen.12445. 
Huang, W.S., Yu, M.D., Lee, M.S., Cheng, C.Y., Yang, S.P., Chin, H.M., Wu, S.Y. (2004). Effect of treadmill exercise on circulating thyroid hormone measurements. Medical Principles and Practice,13 (1), 15-19. DOI: 10.1159/000074045.

Joseph, N., Chettuvatti, K., Yadav, H., Bharadwaj, H., Kotian, S.M. (2017). Assessment of risk of metabolic syndrome and cardio vascular diseases among medical students in India. Journal of Cardiovascular Disease Research, 8 (3), 89-95.

Korkmaz, L., Sahin, S., Akyuz, A.R., Ziyrek, M., Anaforoglu, I., Kose, M., Erkan, H., Ağaç, M.T., Acar, Z. (2013). Epicardial adipose tissue increased in patients with newly diagnosed subclinical hypothyroidism. Medical Principles and Practice, 22 (1), 42-46. DOI: 10.1159/000340065.

Lee, J., Ha, J., Jo, K., Lim, D.J., Lee, J.M., Chang, S.A., Kang, S.I., King, M.H. (2019). High normal range of free thyroxine is associated with decreased triglycerides and with increased high-density lipoprotein cholesterol based on population representative data. Journal of Clinical Medicine, 8 (6), 758. DOI: 10.3390/jcm8060758.

Lo Sasso, B., Vidali, M., Scazzone, C., Agnello, L., Ciaccio, M. (2019). Reference interval by the indirect approach of serum thyrotropin (TSH) in a Mediterranean adult population and the association with age and gender. Clinical Chemistry and Laboratory Medicine, 57 (10), 1587-1594. DOI: 10.1515/cclm-2018-0957.

Marugo, M., Torre, G., Bernasconi, D., Fazzuoli, L., Cassulo, S., Giordano, G. (1991). Androgen receptors in normal and pathological thyroids. Journal of Endocrinological Investigation, 14, 31-35. DOI: 10.1007/BF03350254.

Matthews, D.R., Hosker, J.P., Rudnsky, A.S., Naylor, B.A., Treacher, D.F., Turner, R.C. (1985). Homeostasis model assessment insulin resistance and bet-cell function from fasting plasma glucose and insulin concentrations in man. Diabetologia, 28 (7), 413-419. DOI: $10.1007 / B F 00280883$.

Pearce, S.H., Brabant, G., Duntas, L.H., Monzani, F., Peeters, R.P., Razvi, S., Wemeau, J.L. (2013). ETA Guideline: Management of subclinical hypothyroidism. European Thyroid Journal, 2 (4), 215-228. DOI: 10.1159/000356507.

Pramfalk, C., Pavlides, M., Banerjee, R., McNeil, C.A., Neubauer, S., Karpe, F., Hodson, L. (2016). Fasting plasma insulin concentrations are associated with changes in hepatic fatty acid synthesis and partitioning prior to changes in liver fat content in healthy adults. Diabetes, 65 (7), 1858-1867. DOI: 10.2337/db16-0236.

Rahbar, A.R., Kalantarhormozi, M., Izadi, F., Arkia, E., Rashidi, M., Pourbehi, F., Daneshifard, F., Rahbar, A. (2017). Relationship between Body Mass Index, Waist-to-Hip Ratio, and serum lipid concentrations and Thyroid-Stimulating Hormone in the euthyroid adult population. Iranian Journal of Medical Sciences, 42 (3), 301-305.

Sayin, I., Erkan, A.F., Ekici, B., Kutuk, U., Corakci, A., Tore, H.F. (2016). Thickening of the epicardial adipose tissue can be alleviated by thyroid hormone replacement therapy in patients with subclinical hypothyroidism. Kardiologia Polska, 74 (12), 1492-1498. DOI: 10.5603/KP.a2016.0053.

Schaefer, C.J., Geelhoed, G.W., Dadu, P. (1986). Thyroid disorders and steroid receptor proteins. he American Surgeon, 52 (9), 514-518.

Scherer, T., Lindtner, C., O’Hare, J., Hackl, M., Zielinski, E., Freudenthaler, A., Baumgartner-Parzer, S., Tödter, K., Heeren, J., Krššák, M., Scheja, L., Fürnsinn, C., Buettner, C. (2016). Insulin regulates hepatic triglyceride secretion and lipid content via signaling in the brain. Diabetes, 65 (6), 1511-1520. DOI: 10.2337/db15-1552.

Sinha, R.A., Singh, B.K., Yen, P.M. (2018). Direct effects of thyroid hormones on hepatic lipid metabolism. Nature Reviews Endocrinology, 14 (5), 259-269. DOI: 10.1038/nrendo.2018.10.

Tognini, S., Polini, A., Pasqualetti, G., Ursino, S., Caraccio, N., Ferdeghini, M., Monzani, F. (2012). Age and gender substantially influence the relationship between thyroid status and the lipoprotein profile: results from a large cross-sectional study. Thyroid, 22 (11), 1096-1103. DOI: 10.1089/thy.2012.0013.

Wang, D.C., Li, D.D., Guo, X.Z., Yu, S.L., Qiu, L., Cheng, X.Q., Xu, T., Li, H., Liu, H. (2018). Effects of sex, age, sampling time, and season on thyroid-stimulating hormone concentrations: a retrospective study. Biochemical and Biophysical Research Communications, 506 (3), 450-454. DOl: 10.1016/j.bbrc.2018.10.099.

Cite this article aS: Malara, M., Kęska, A., Tkaczyk, J., Lutosławska, G. (2021). Normal Levels of TSH Affect the Metabolic Profile Differently in Physically Active Males and Females. Central European Journal of Sport Sciences and Medicine, 3 (35), 41-48. DOI: $10.18276 / c e j .2021 .3-04$. 